\title{
Anatomy of the long peroneal muscle of the leg
}

\author{
U. Bogacka, D. Dziedzic, I. Komarnitki, B. Ciszek \\ Department of Descriptive and Clinical Anatomy, Medical University of Warsaw, Poland
}

[Received: 20 April 2016; Accepted: 4 July 2016]

Background: The aim of the work was to perform a morphometric analysis of the long peroneal muscle (LPM) of the leg and explore the relationship between muscle belly and tendon.

Materials and methods: Ten lower limbs (8 right and 2 left) were fixed in formaldehyde and dissected using standard technique. The LPM was exposed from the proximal attachment to the top of a lateral malleolus.

Results: The tendon was subsequently freed and various measurements were taken. The tendon of the LPM enters deep into the muscle belly. Muscle fibres surround the tendon and descend as far down as $4 \mathrm{~cm}$ above the lateral malleolus. Muscle fibres insert mainly along posterior border of the tendon and on its medial surface, leaving lateral surface only partly covered.

Conclusions: The LPM contains a long intramuscular segment of the tendon and area of the musculotendinous junction varies along the LPM. It makes the idea of uniform pennation pattern of the LPM unlikely. (Folia Morphol 2017; 76, 2: 284-288)

Key words: peroneus longus muscle, leg, locomotor system, tendon, ankle, muscle, myology

\section{INTRODUCTION}

Proximal attachment of the long peroneal muscle (LPM) is separated into two parts by the common peroneal nerve, which goes in between. The first part, also known as superficial or the superficial head [1], has its origin on the head of the peroneal bone, the lateral condyle of tibia and the capsule of tibiofibular syndesmosis, whereas the second part, called a deep head [1, 2], begins in the upper part of lateral surface of the peroneal bone from appropriate parts of the anterior and posterior intermuscular septum of the leg and from deep fascia of the leg $[1,11]$.

Its tendon lies on the short peroneal muscle in the longitudinal groove of its tendon and $4 \mathrm{~cm}$ above the lateral malleolus they descend together through the common peroneal synovial sheath into a fibro-osseous tunnel $[8,13,22]$. The tendon enters the plantar region and inserts into the base of first metatarsus and medial cuneiform bone. The LPM plays important role in supporting the arch of the foot [14, 19, 21, 22].

Peroneus longus and peroneus brevis muscles are the primary pronators of the foot. Their tendons pass posteriorly, but in close proximity to the lateral malleous, which enables them to act as secondary plantar flexors [21]. A group of peroneal muscles generates only $4 \%$ of strength, while a triceps surae muscle generates $84 \%$ of strength produced during this movement [11]. In practice, the most important function of the longus and brevis muscles is to depress or to hold stable the first ray of the foot in the toe-off phase of gait, to stabilize the ankle joint and support the architecture of the foot [21].

There is a lot of data regarding external morphology of the peroneus longus muscle while the

Address for correspondence: Dr. I. Komarnitki, Department of Descriptive and Clinical Anatomy, Medical University of Warsaw, ul. Chałubińskiego 5, 02-004 Warszawa, Poland, e-mail: anatomy@onet.eu 


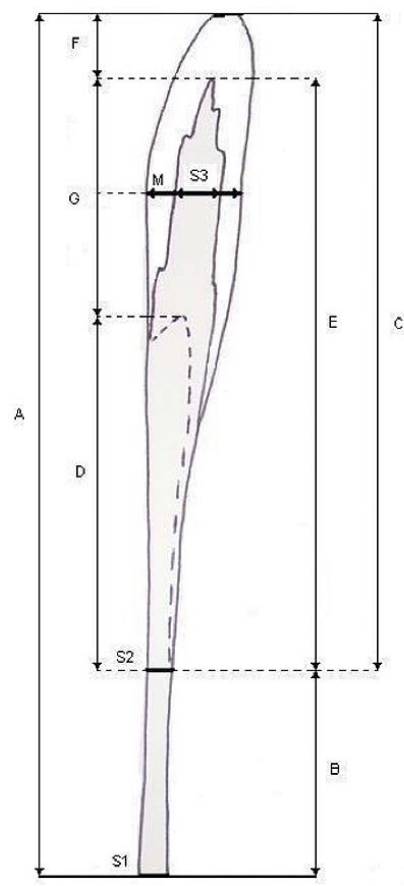

Figure 1. Schematic representation of the peroneus longus muscle with a diagram of performed measurements; $A$ - length of the muscle; $\mathrm{B}$ - length of the tendon alone; $\mathrm{C}$ - maximal diameter of muscle belly; $\mathrm{D}$ - difference between maximal and minimal dimensions of muscle belly; $\mathrm{E}$ - length of the tendon "infiltrating" the belly; $\mathrm{F}$ - length of the belly alone; $\mathrm{G}$ - length of the tendon completely immersed in the muscle belly; $\mathrm{S} 1$ - width of the tendon measured at the level of lateral malleolus; S2 - width of the tendon measured at the level of maximal length of muscle fibres; S3 - width of the tendon measured at the G level; $\mathrm{M}$ - width of the muscle belly measured at the $\mathrm{G}$ level.

relationships of the internal muscle tendon are not clear. It is an important problem from the point of view of biomechanics of the leg and foot, prompting the present study.

\section{MATERIALS AND METHODS}

Material came from the Department of Descriptive and Clinical Anatomy at the Medical University of Warsaw. Ten lower limbs, 8 right and 2 left, fixed in a $5 \%$ formaldehyde solution were used to conduct this study. Relative length of limbs measured from the anterior superior iliac spine to the medial ankle ranged $74-88 \mathrm{~cm}$ (mean $80.9 \pm 4.72 \mathrm{~cm}$ ).

After removing the skin and opening the deep fascia of the leg, the LPM was dissected from its proximal attachment at the fibular head all the way to lateral malleolus. It was subsequently measured on outside - from the head of fibula to the lateral malleolus. The following measurements were performed (Fig. 1).
Results were collected in a Microsoft Office Excel 2007 spreadsheet program. Statistical analysis of the results was performed using STATISTICA software by StatSoft Co. A Spearman coefficient was used to the calculate correlations

\section{RESULTS}

The tendon of peroneus longus muscle enters very deeply into the muscle belly, its thin fascicle reaching as far up as $1 \mathrm{~cm}$ from the head of fibula, whereas the belly embracing the tendon goes down and ends in a small number of fibres up to $4 \mathrm{~cm}$ above the lateral malleolus.

Inside of the belly of LPM, muscle fibres run and connect with the tendon bilaterally, as shown in pictures depicting various stages of dissection (Figs. 2-5).

After dissecting muscle fibres on the lateral and medial sides of the tendon, it was possible to perform macroscopic comparison. The lateral side of the tendon was characterised by relatively even surface (Figs. 3, 4), while the medial surface had a specific structure resembling a harmonica (Fig. 5). As shown in the photos (Figs. 4, 5), minimal range of the muscular belly is located on the lateral side. Similar structures were noted in all specimens. On the other hand, the maximal span of the muscle belly in all studied specimen was marked by a narrow strand on the posterior edge of the tendon (Figs. 4, 5).

Investigated segment of the LPM was measured from its proximal attachment on the head of peroneal bone to the lateral malleolus - measurement " $\mathrm{A}$ ". This distance ranges between 27.0 and $34.5 \mathrm{~cm}$, with average length of $31.55 \pm 2.5 \mathrm{~cm}$.

On the outside muscle belly was conical in shape, with its base turned to the head of the peroneal bone, and went down with a thin strand of fibres toward the lateral malleolus. Then, we took external measurements of the muscle belly, which included a muscle tendon and went down as a thin fascicle measuring from 20 to $28 \mathrm{~cm}$, mean of $25.05 \pm 2.63 \mathrm{~cm}$.

A difference between maximal and minimal span of the belly ranged from 10 to $15.5 \mathrm{~cm}$, while the average length was $12.4 \pm 1.91 \mathrm{~cm}$. The tendon was measured from the outside before dissection and divided into two sections: section I, partially covered by the belly, was equal to the difference between maximal and minimal span of the belly. Its length ranged from 10.0 to $15.5 \mathrm{~cm}$. Section II that ran beyond the muscle belly was from 4 to $9 \mathrm{~cm}$ in length, mean of $6.5 \pm 1.89 \mathrm{~cm}$. After cutting the muscle belly and 


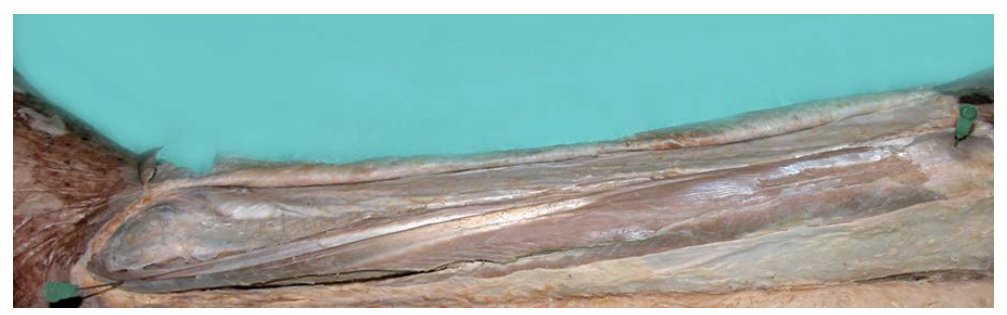

Figure 2. The long peroneal muscle in situ; right lower limb.

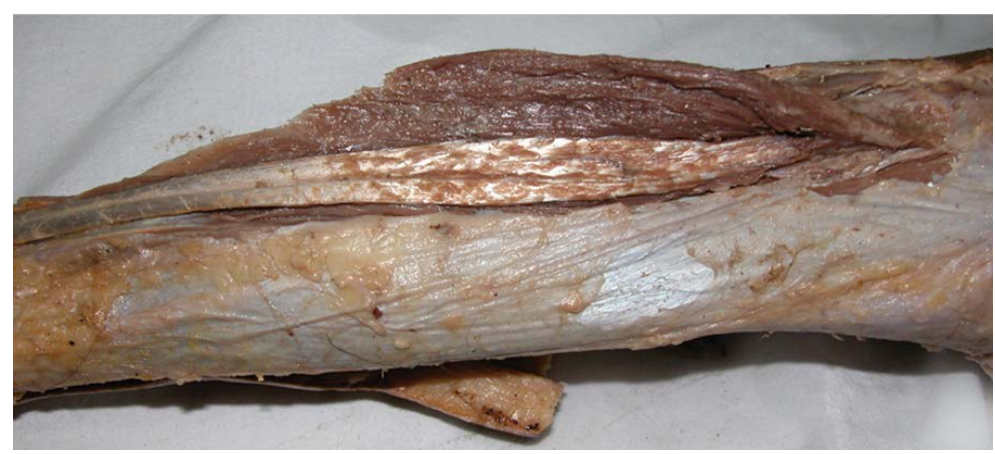

Figure 3. The long peroneal muscle; view of the lateral side of the tendon running in the muscular belly following dissection and cutting of the peroneal part of the belly; right lower limb.

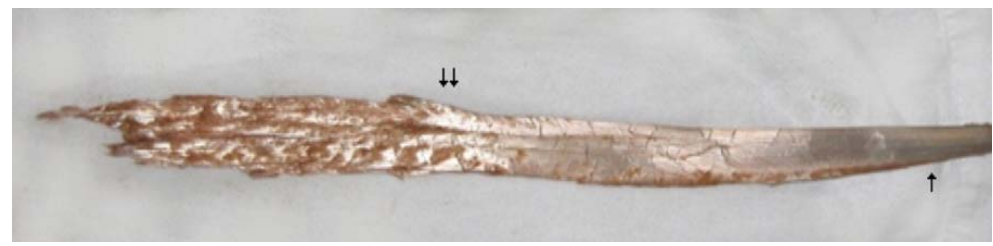

Figure 4. Long peroneal muscle tendon — lateral view; minimal (two arrows) and maximal (one arrow) span of the muscle belly was marked; right lower limb.

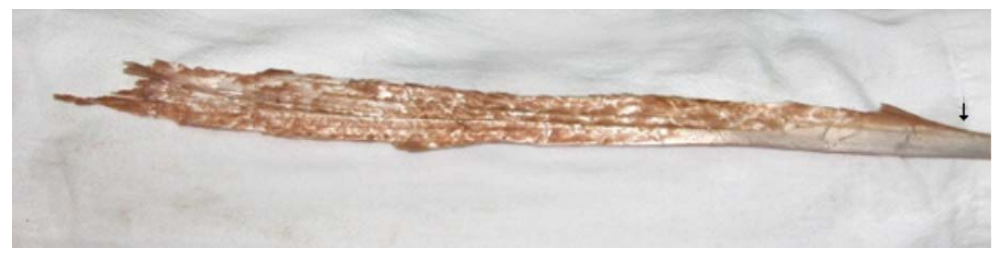

Figure 5. Tendon of the long peroneal muscle — medial view; maximal span of the muscle belly — arrow; right lower limb.

exposing the tendon inside, its length was measured. The length of the tendon within muscle belly was $8-13 \mathrm{~cm}$, which after adding to the remaining length of the tendon gives a total distance ranging between 24.0 and $32.5 \mathrm{~cm}$. Relative length of limbs measured from the anterior superior iliac spine to the medial ankle varied from 74 to $88 \mathrm{~cm}$, with mean length of $80.9 \pm 4.72 \mathrm{~cm}$. Subsequently, we measured the width of the tendon and the muscle. The tendon was measured at three levels: at the level of lateral malleolus, the level of maximal width of muscle fibres and at the half length of the tendon inside the muscle belly, where the width of muscle belly was also measured. Measured width values were as follows:

- I - width of the tendon was $0.4-0.9 \mathrm{~cm}$, mean $0.66 \pm 0.17 \mathrm{~cm}$; 
— II - width ranged $0.6-1.2 \mathrm{~cm}$, mean $0.85 \pm 0.19 \mathrm{~cm}$, while

— III - width ranged 1.6-2.1, mean $1.88 \pm 0.17 \mathrm{~cm}$. Length of the muscle belly alone was 1.0 to $4.0 \mathrm{~cm}$, mean $2.5 \pm 1.03 \mathrm{~cm}$, while the width of the belly varied between 2.0 and $3.5 \mathrm{~cm}$.

\section{DISCUSSION}

Relative lengths of limbs used for the study were in the range of anthropological characteristics for white Caucasian population; therefore, limited number of investigated specimen does not affect the importance of obtained results $[6,10]$.

The LPM is quite often described in the literature, but the descriptions most often relate to the LPM as well as the brevis peroneal muscle $[4,5,18,20]$. Data regarding morphometry is also infrequent $[12,17]$. The majority of descriptions refer to the attachments of the LPM, tendon injury or the influence of the LPM on foot biomechanics $[3,7,9,11,15,16,20,22]$.

In our research the observed proximal attachment of the LPM and its course to the lateral malleolus agreed with descriptions in available literature $[15,20,22]$. The distal attachment was not the subject of this work. Descriptions of the LPM belly morphology are also limited [15, 20, 22]. Morphometric descriptions of the LPM are conflicting. For example, according Liber [17] the length of the whole muscle was $286 \pm 17 \mathrm{~mm}$, although it was not said precisely how this length had been measured. There is no information if the examined muscles came from adults or children, whether they were measured from their origins to distal attachments, a part of the muscle or its belly alone. It is difficult to compare these results with those obtained in our study. The length of the tendon according to Horsman et al. [12] amounted to $15.9 \mathrm{~cm}$, but they measured the length in one, $174-\mathrm{cm}$-tall individual, making this information rather anecdotic. Again it is difficult to compare this value with the results obtained by the authors, as it is unknown whether the tendon was measured entirely after dissection of the muscle belly, from its origin inside the muscle all the way to its insertion or just the section of the tendon visible to the naked eye.

No reports regarding the span of the tendon within muscle belly as well as the span of a muscle belly alone were available in the literature. Variability of muscle belly morphology observed in our study, especially concerning its lower part may lead to tissue conflict with the retinaculum of peroneal muscles or modify the course of the fascial compartment syndrome.

Long peroneal muscle is described as bipennate or circumpennate (radial) [22] muscle. In fact, muscle fibres are attached to $10-100 \%$ of the tendon surface and the tendon itself is a flat lamina of tendinous tissue. Thus, muscle morphology varies from unipennate, by halfpennate, 3/4-pennate and circumpennate muscle making the concept of pennation a matter for future discussions. Observations in the area of muscle fibre attachment to the tendon indicate its close relationship to the actual cross section of the whole fibres, which reflect the potential force produced by the muscle. The long intramuscular segment of the tendon - not reported by other investigators - focuses the attention on imaging of a possible pathology of the musculotendinous junction in cases of functional ankle instability.

\section{CONCLUSIONS}

1. The muscle belly of the LPM is shaped as a long cone with its base turned toward the head of fibula, with long protrusion descending along the posterior edge of the tendon.

2. The muscle of LPM belly contains a long, flat intramuscular part of the tendon.

3. The character of pennation of the LPM changes along the tendon.

\section{REFERENCES}

1. Aigner F, Longato S, Gardetto A, et al. Anatomic survey of the common fibular nerve and its branching pattern with regard to the intermuscular septa of the leg. Clin Anat. 2004; 17(6): 503-512, doi: 10.1002/ca.20007, indexed in Pubmed: 15300871.

2. Bakkum BW, Russell K, Adamcryck T, et al. Gross anatomic evidence of partitioning in the human fibularis longus and brevis muscles. Clin Anat. 1996; 9(6): 381-385, doi: 10.1002/ (SICI)1098-2353(1996)9:6<381::AID-CA4>3.0.CO;2-E, indexed in Pubmed: 8915617

3. Blitz NM, Nemes KK. Bilateral peroneus longus tendon rupture through a bipartite os peroneum. J Foot Ankle Surg. 2007; 46(4): 270-277, doi: 10.1053/j.jfas.2007.03.006, indexed in Pubmed: 17586440.

4. Borton DC, Lucas P, Jomha NM, et al. Operative reconstruction after transverse rupture of the tendons of both peroneus longus and brevis. Surgical reconstruction by transfer of the flexor digitorum longus tendon. J Bone Joint Surg Br. 1998; 80(5): 781-784, indexed in Pubmed: 9768886.

5. Casillas M. Operative treatment of peroneusbrevis and peroneus longus tendon tears. Oper Techn Sports Med. 2001; 9(1): 14-19, doi: 10.1053/otsm.2001.21918. 
6. Chiang ER, Ma HL, Wang ST, et al. Hamstring graft sizes differ between Chinese and Caucasians. Knee Surg Sports Traumatol Arthrosc. 2012; 20(5): 916-921, doi: 10.1007/ s00167-011-1653-3, indexed in Pubmed: 21866349.

7. Davies JA. Peroneal compartment syndrome secondary to rupture of the peroneus longus. A case report. J Bone Joint Surg Am. 1979; 61(5): 783-784, indexed in Pubmed: 457726.

8. Domagała Z, Gworys B, Porwolik K. Preliminary assessment of anatomical variability of nervus peroneus superficialis in the foetal period. Folia Morphol. 2003; 62(4): 401-403, indexed in Pubmed: 14655126.

9. Dombek MF, Lamm BM, Saltrick K, et al. Peroneal tendon tears: a retrospective review. J Foot Ankle Surg. 2003; 42(5): 250-258, indexed in Pubmed: 14566716.

10. Duda GN, Brand D, Freitag S, et al. Variability of femoral muscle attachments. J Biomech. 1996; 29(9): 1185-1190, indexed in Pubmed: 8872275.

11. Heckman DS, Reddy S, Pedowitz D, et al. Operative treatment for peroneal tendon disorders. J Bone Joint Surg Am. 2008; 90(2): 404-418, doi: 10.2106/JBJS.G.00965, indexed in Pubmed: 18245603.

12. Horsman MDK, Koopman H, Helm F, et al. Morphological muscle and joint parameters for musculoskeletal modelling of the lower extremity. Clin Biomech. 2007; 22(2): 239-247, doi: 10.1016/j.clinbiomech.2006.10.003.

13. Jayakumari S, Suri RK, Rath G, et al. Accessory tendon and tripartite insertion pattern of fibularis longus muscle: a case report. Int J Morphol. 2006; 24(4): 633-636, doi: $10.4067 / \mathrm{s} 0717-95022006000500019$.
14. Kokubo T, Hashimoto T, Nagura T, et al. Effect of the posterior tibial and peroneal longus on the mechanical properties of the foot arch. Foot Ankle Int. 2012; 33(4): 320-325, doi: 10.3113/FAl.2012.0320, indexed in Pubmed: 22735204.

15. Kopsch FR. Lehrbuch und Atlas der Anatomie des Menschen. Vol. I, III. Arbeitsgemeinschaft medizinischer Verlage G.M.B.H.; Georg Thieme-Leipzig 1952.

16. Larsen C. Spiraldynamik: Prävention von Fussdeformitaten, Krankengymnastik Zeitschrift für Physiotherapeuten. 1998; 50(9): 1534-1544.

17. Lieber RL. Skeletal muscle structure, function and plasticity, Lippincott Williams\&Wilkins, Philadelphia. 2002.

18. Raheja S, Choudhry R, Singh P, et al. Morphological description of combined variation of distal attachments of fibulares in a foot. Surg Radiol Anat. 2005; 27(2): 158-160, doi: 10.1007/ s00276-004-0290-7, indexed in Pubmed: 15580345.

19. Ryan W, Mahony N, Delaney M, et al. Relationship of the common peroneal nerve and its branches to the head and neck of the fibula. Clin Anat. 2003; 16(6): 501-505, doi: 10.1002/ca.10155, indexed in Pubmed: 14566896.

20. Sammarco GJ, Mangone PG. Diagnosis and treatment of peroneal tendon injuries. Foot Ankle Surgery. 2000; 6(4): 197-205, doi: 10.1046/j.1460-9584.2000.00212.x.

21. Sarig-Bahat $H$, Krasovsky A, Sprecher E. Evaluation of clinical methods for peroneal muscle testing. Physiother Res Int. 2013; 18(1): 55-62, doi: 10.1002/pri.1534, indexed in Pubmed: 22911954.

22. Warwick R, Williams P, Dyson M, et al. Gray's Anatomy. Churchill Livingstone Edinburgh London Melbourne and New York. 1989. 